ROSSI, M. A. L. S. et al. Síntese de catalisador Redox a base de óxido de ferro magnético suportado em sílica utilizando níquel como promotor

\title{
SÍNTESE DE CATALISADOR REDOX A BASE DE ÓXIDO DE FERRO MAGNÉTICO SUPORTADO EM SÍLICA UTILIZANDO NÍQUEL COMO PROMOTOR $^{1}$
}

\author{
Marco Aurélio de Lima Silva Rossi ${ }^{2}$ \\ Ricardo Velloso Lelo ${ }^{3}$ \\ William Miguel da Silva Borges ${ }^{4}$ \\ Mário César Guerreiro ${ }^{5}$
}

\begin{abstract}
RESUMO
Foi realizada a síntese de um catalisador baseado em óxido de ferro magnético promovido com níquel e suportado em sílica. O material foi caracterizado por microscopia eletrônica de varredura com detector de energia dispersiva de raios-X (MEV-EDS) e difratometria de raios$\mathrm{X}$ (DRX) e testado como catalisador na oxidação do composto orgânico modelo azul de metileno (AM) utilizando o processo foto-Fenton que obteve uma atividade satisfatória para o catalisador com mais 75\% de descoloração após 10 minutos de reação.
\end{abstract}

Palavras-chave: Óxido de Ferro Magnético. Níquel. Sílica. Catálise. Foto-Fenton.

\section{INTRODUÇÃO}

Dentre a grande variedade de óxidos existentes, os óxidos de ferro representam uma família de materiais com notável diversidade de propriedades magnéticas, elétricas, físicoquímicas e morfológicas, que os tornam muito importantes do ponto de vista científico e tecnológico (CORNELL; SCHWERTMANN, 2003).

Nesse âmbito, muitos processos podem ser utilizados para aumentar a eficiência catalítica, conversão e seletividade dos óxidos. Um dos processos mais promissores, segundo McFarland e Metiu (2013) é a introdução de espécies catiônicas distintas como promotoras

\footnotetext{
${ }^{1}$ Como citar este artigo:

ROSSI, M. A. de L S et al. Síntese de catalizador Redox a base de óxido de ferro magnético suportado em sílica utilizando níquel como promotor. ForScience: revista científica do IFMG, Formiga, v. 5, n. 2, e00286, out. 2017. Edição especial.

${ }^{2}$ Doutorando em Química pelo Instituto de Química de São Carlos da Universidade de São Paulo (IQSC/USP). Mestrado em Química pela Rede Mineira de Química pela Universidade Federal de Lavras (UFLA). Currículo Lattes: http://lattes.cnpq.br/9217040796158340. E-mail: marcoalsrossi@ gmail.com.

${ }^{3}$ Doutorando em Química pela Universidade Federal de Santa Catarina (UFSC). Mestrado em Agroquímica pela UFLA. Currículo Lattes: http://lattes.cnpq.br/9816621415864153. E-mail: rvlelo@gmail.com.

${ }^{4}$ Doutorando em Química pela Rede Mineira de Química e Mestre em Agroquímica pela UFLA. Currículo Lattes: http://lattes.cnpq.br/0070441619535641.E-mail: will_msb@ hotmail.com.

${ }^{5}$ Doutorado e Mestrado em Química pela Universidade Estadual de Campinas (UNICAMP). Atualmente é professor Associado I do Departamento de Química da Lavras. Currículo Lattes:

http://lattes.cnpq.br/2564511433554475. E-mail: guerreiro@dqi.ufla.br.
}

ForSci.: r. cient. IFMG campus Formiga, Formiga, v. 5, n. 2, e00286, out. 2017. Edição especial. 
ROSSI, M. A. L. S. et al. Síntese de catalisador Redox a base de óxido de ferro magnético suportado em sílica utilizando níquel como promotor

que apresentem propriedades de interesse, como o níquel, que apresenta múltiplos estados de oxidação e propriedades catalíticas semelhantes a paládio e platina. Porém, o uso de níquel apresenta custo bem inferior (TASKER; STANDLEY; JAMISON, 2014).

Outro modo de aumentar a atividade catalítica dos óxidos envolve a dispersão de suas partículas sobre um suporte inorgânico e, nesse aspecto a sílica se evidencia como um material muito vantajoso em virtude de suas características, pois confere proteção para as partículas, previne o processo de lixiviação num ambiente ácido e aumenta a sua estabilidade térmica e química (MAZALEYRAT et al., 2009).

Dentre as possíveis reações catalisadas por óxidos com propriedades de oxirredução adequadas, os processos de oxidação avançada se destacam como alternativa muito eficiente para a remoção de poluentes persistentes presentes em efluentes industriais e corpos d'água. $\mathrm{O}$ processo mais comum é o denominado Fenton, no qual $\mathrm{Fe}^{2+}$ e $\mathrm{H}_{2} \mathrm{O}_{2}$, em pH ácido, possibilitam a geração de radicais hidroxila responsáveis pela degradação da matéria orgânica tóxica. Existem também as variações do processo Fenton, como exemplo o fotoFenton, quando tal reação é potencializada pela irradiação de luz ultravioleta.

Com base nisso, o presente trabalho tem por objetivo a síntese da avaliação da atividade de um catalisador baseado em óxido de ferro magnético suportado em sílica fumed amorfa e promovido com níquel em reações oxidativas do tipo foto-Fenton.

\section{MATERIAIS E MÉTODOS}

\subsection{Síntese}

$\mathrm{O}$ catalisador foi sintetizado através das pesagens de massas $\mathrm{FeCl}_{3} \cdot 6 \mathrm{H}_{2} \mathrm{O}$ e de $\mathrm{FeCl}_{2} \cdot 4 \mathrm{H}_{2} \mathrm{O}$, de modo que a proporção molar entre os íons $\mathrm{Fe}^{2+}$ para $\mathrm{Fe}^{3+}$ fosse de 1:2. Os sais foram dissolvidos em água previamente tratada com borbulhamento de $\mathrm{N}_{2}$ juntamente com uma massa de $\mathrm{Ni}\left(\mathrm{NO}_{3}\right)_{2} \cdot 3 \mathrm{H}_{2} \mathrm{O}$ que representasse 2,5\% em mol de níquel em relação ao ferro total. Toda a síntese foi feita em ambiente inerte pelo borbulhamento de gás nitrogênio, com ultrassom e agitação mecânica vigorosa. Após 30 minutos de agitação, foi gotejada solução de hidróxido de amônio até que o pH atingisse um valor em torno de 11 e a solução apresentasse uma coloração preta. 
ROSSI, M. A. L. S. et al. Síntese de catalisador Redox a base de óxido de ferro magnético suportado em sílica utilizando níquel como promotor

Após esse ponto, a mistura permaneceu em agitação por cerca de 30 minutos, após os quais, cinco gramas de sílica fumed foram adicionados. O sistema permaneceu em agitação por mais 30 minutos e após esse tempo o catalisador obtido foi deixado em descanso por 72 horas, lavado até $\mathrm{pH}$ neutro e seco em estufa por 24 horas à $60^{\circ} \mathrm{C}$. O pó resultante foi passado por um moinho de bolas para homogeneização da granulometria do material e posteriormente submetido à peneiração, objetivando a dimensão máxima de 0,25mm (60 Mesh).

\subsection{Caracterizações}

A composição química foi analisada por microscopia eletrônica de varredura com detector de energia dispersiva de raios-X (MEV-EDS), utilizando um aparato LEO EVO 40XVP, com tensão de $25 \mathrm{keV}$. Os elementos foram mapeados por energia dispersiva de raios-X em um equipamento EDS/INCA 350. O difratograma foi obtido utilizando-se um difratômetro Rigaku Geigerflex, com tubo de cobre $(\mathrm{K} \alpha=1,54056 \AA$ ), velocidade de varredura de $1^{\circ} \theta \mathrm{min}^{-1}, 5$ s por incremento com variação angular de $20^{\circ}$ a $75^{\circ}$.

\subsection{Testes Catalíticos}

A atividade catalítica do material foi avaliada pela reação de oxidação do composto orgânico modelo, seguindo o sistema foto-Fenton que foi realizado utilizando $60 \mathrm{~mL}$ da solução de azul de metileno $\left(50 \mathrm{mg} \mathrm{L}^{-1}\right), 20 \mathrm{mg}$ de material e $0,06 \mathrm{~mL}$ de solução de $\mathrm{H}_{2} \mathrm{O}_{2}$ (50\%) expostas, em agitação, a uma lâmpada UV com $15 \mathrm{~W}$ de potência com comprimento de onda igual a $254 \mathrm{~nm}$. O branco foi realizado utilizando $60 \mathrm{~mL}$ da solução de azul de metileno (50 $\mathrm{mg} \mathrm{L}^{-1}$ ) e $0,06 \mathrm{~mL}$ de solução de $\mathrm{H}_{2} \mathrm{O}_{2}(50 \%)$ expostas às mesmas condições. Em intervalos pré-determinados as amostras foram retiradas e a concentração remanescente foi determinada por espectroscopia de UV-Visível, no comprimento de onda correspondente a $665 \mathrm{~nm}$, em um espectrômetro Shimadzu UV-1601 PC.

Testes de adsorção foram realizados através do contato entre o $10 \mathrm{mg}$ de material e 10 $\mathrm{mL}$ de solução de corante na concentração de $50 \mathrm{mg} . \mathrm{L}^{-1}$ por $24 \mathrm{~h}$ nas mesmas condições em que o processo catalítico se deu, incluindo a irradiação por luz ultravioleta. 
ROSSI, M. A. L. S. et al. Síntese de catalisador Redox a base de óxido de ferro magnético suportado em sílica utilizando níquel como promotor

Testes de lixiviação foram realizados adicionando-se $0,5 \mathrm{~mL}$ de corante $1000 \mathrm{mg} . \mathrm{L}^{-1} \mathrm{e}$ $0,1 \mathrm{~mL}$ de peróxido de hidrogênio a $9,5 \mathrm{~mL}$ de sobrenadante da primeira solução degradada com o intuito de avaliar a atividade do possível material lixiviado e presente em solução.

\section{RESULTADOS E DISCUSSÃO}

\subsection{Difração de Raios X}

A Figura 1 apresentada abaixo evidencia o difratograma de raios $\mathrm{X}$ para o catalisador sintetizado

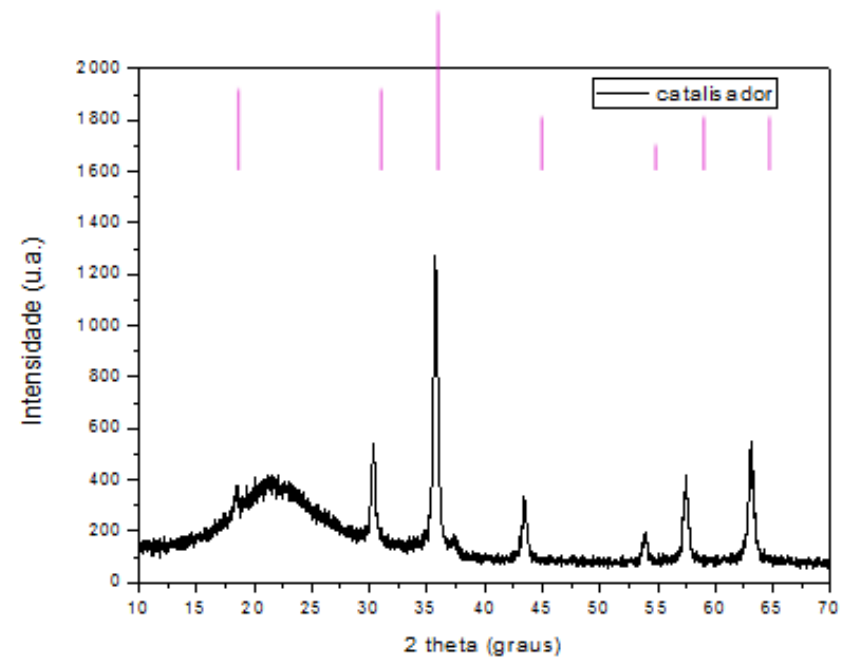

Figura 1 - Difratograma de raios X para o catalisador sintetizado.

Fonte: Elaborado pelos autores.

Nota: As linhas em rosa correspondem ao padrão cristalográfico JCPDS 19-0629 da estrutura de magnetita.

Pelas análises de difração de Raios $\mathrm{X}$, foi possível verificar que o padrão cristalográfico do material sintetizado é compatível à carta cristalográfica JCPDS 19-0629 da magnetita $\left(\mathrm{Fe}_{3} \mathrm{O}_{4}\right)$. A presença de material amorfo evidenciada pelo deslocamento da linha base entre 15 e $30^{\circ}$ pode ser atribuída à sílica fumed, utilizada como suporte, de estrutura conhecidamente amorfa.

\subsection{Microscopia eletrônica de varredura com detector de energia dispersiva de raios-X - (MEV/EDS)}


ROSSI, M. A. L. S. et al. Síntese de catalisador Redox a base de óxido de ferro magnético suportado em sílica utilizando níquel como promotor

Através da análise de MEV/EDS (ver FIGURA 2) obteve-se a micrografia do material, que não apresenta aglomeração de partículas e demonstra-se bem disperso.

Por meio da análise elementar foi possível investigar quais átomos estão presentes no catalisador, tendo sido encontrados níquel; silício; oxigênio e ferro, que eram todos esperados a partir do método de síntese proposto.

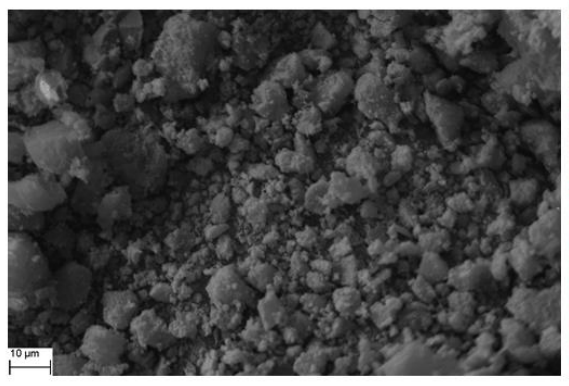

(a)

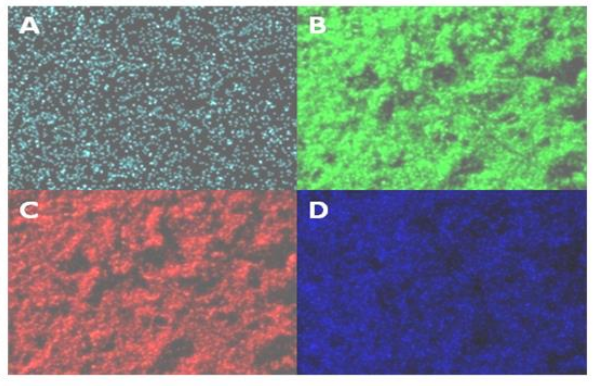

(b)

Figura 2 - a) Análise por microscopia eletrônica de varredura para o material sintetizado; b) Espectro de análise elementar gerado pelo detector EDS. (A) Níquel, (B) Silício, (C) Oxigênio, (D) Ferro Fonte: Elaboração dos autores.

\subsection{Testes catalíticos (foto-Fenton)}

Verificou-se que a atividade do catalisador na degradação do corante foi satisfatória tendo gerado mais de $75 \%$ de descoloração em apenas 10 minutos de processo reacional.

Testes relacionados à descoloração por adsorção apresentaram resultado desconsiderável, sendo a descoloração em virtude desse processo praticamente nula, próxima a $1 \%$.

Testes relacionados à lixiviação evidenciaram uma atividade muito baixa dos compostos presentes no sobrenadante após a primeira degradação, representando cerca de $4 \%$ da atividade do material heterogêneo.

O teste realizado encontra-se evidenciado na Figura 3: 
ROSSI, M. A. L. S. et al. Síntese de catalisador Redox a base de óxido de ferro magnético suportado em sílica utilizando níquel como promotor

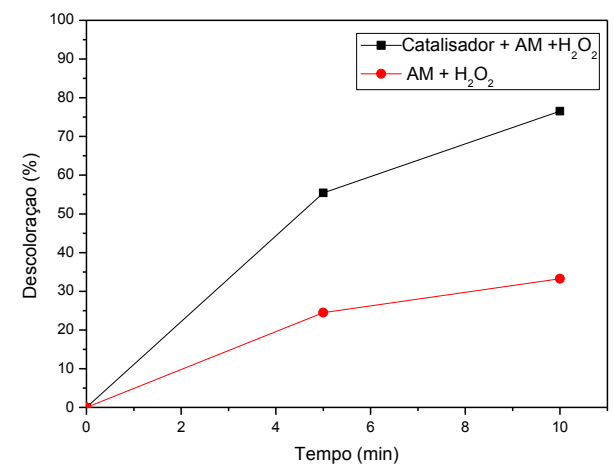

Figura 3 - Cinética de degradação do corante azul de metileno empregando-se o catalisador sintetizado, peróxido de hidrogênio e luz ultravioleta Fonte: Elaborado pelos autores.

\section{CONCLUSÃO}

O material sintetizado promovido com níquel e suportado em sílica, tendo como fase cristalina preponderante a magnetita, apresentou resultados satisfatórios quanto à atividade catalítica na degradação do corante azul de metileno pelo processo foto-Fenton em um mecanismo heterogêneo de degradação no qual a atividade dos metais lixiviados em solução e o fenômeno de adsorção se mostraram desconsideráveis.

\section{REFERÊNCIAS}

CORNELL, R. M.; SCHWERTMANN, R. M. The iron oxides: structure, properties, reactions, occurences and uses. 2. ed. Weinheim: Wiley-VCH, 2003.

MAZALEYRAT, F. et al. Silica coated nanoparticles: synthesis, magnetic properties and spin structure. Journal of Alloys Compounds, v. 483, p. 473-478, 2009.

MCFARLAND, E. W.; METIU, H. Catalysis by doped oxides. Chemical Reviews, v. 113, n. 6, p. 4391-427, 2013.

TASKER, S.; STANDLEY, E.; JAMISON, T. Recent advances in nickel homogeneous catalysis. Nature, v. 509, p. 299-309, 2014. 
ROSSI, M. A. L. S. et al. Síntese de catalisador Redox a base de óxido de ferro magnético suportado em sílica utilizando níquel como promotor

\title{
SYNTHESIS OF NICKEL PROMOTED MAGNETIC IRON OXIDE REDOX CATALYST SUPPORTED ON SILICA
}

\begin{abstract}
A catalyst based on magnetic iron oxide promoted with nickel and supported on silica was synthesized. The material was characterized by scanning electron microscopy with dispersive X-ray energy detector (SEM-EDS) and X-ray diffractometry (XRD). It was tested as a catalyst in the oxidation of the methylene blue organic compound using Photo-Fenton process in which a satisfactory activity was obtained for the catalyst with over $75 \%$ decolorization after 10 minutes of reaction.
\end{abstract}

Keywords: Magnetic Iron Oxide. Nickel. Silica. Catalysis. Photo-Fenton.

Recebido em: 24/06/2016

Aprovado em: 15/07/2016

Publicado em: 06/10/2017 